\title{
AZORÍN. O Político. Tradução de Jaimir Conte. Florianópolis: EdUFSC, 2015, 131 p.
}

Ítalo Lins Lemos

Universidade Federal de Santa Catarina Florianópolis, Santa Catarina, Brasil

José Augusto Trindad Martínez Ruiz (1873-1967), mais conhecido pelo pseudônimo "Azorín”, nasceu em Monóvar, cidade localizada na região sudeste da Espanha. Azorín é considerado um dos escritores mais influentes de seu tempo, sendo não apenas um dos fundadores, mas também um dos principais representantes da chamada Generación del 98 - grupo de intelectuais espanhóis que reuniu nomes como o escritor Miguel de Unamuno e, algumas décadas mais tarde, na Generación del 14, o filósofo José Ortega y Gasset. Exerceu ainda a profissão de jornalista, tendo escrito para periódicos como El País, La Campaña, El Progreso e El Imparcial. Participou ativamente da vida política espanhola, sendo um grande crítico do governo de Franco. A sua bibliografia é extensa e estilisticamente variada: escreveu de ensaios, romances, contos a peças de teatro. Analisaremos aqui a tradução brasileira de $O$ Político, que é um conjunto de máximas e aconselhamentos direcionado (mas não restrito) aos políticos de sua época, publicado originalmente em espanhol no ano de 1908.

A obra foi traduzida por Jaimir Conte, que é professor de Filosofia da Universidade Federal de Santa Catarina; e foi publicada pela editora da mesma universidade, a EDUFSC, em 2015. Jaimir possui ampla experiência na área de tradução, tendo publicado tra- 
duções de livros e artigos da área de filosofia a partir do inglês, francês, italiano e espanhol. Dentre as traduções mais aclamadas estão Os Céticos Gregos de Victor Brochard, História Natural da Religião de David Hume e Ceticismo e Naturalismo de Peter Strawson. $O$ Político, por sua vez, não é apenas a primeira tradução de Jaimir a partir do espanhol, mas também a primeira tradução de um texto de Azorín para o nosso idioma.

O Político é um livro de aconselhamentos filosóficos que possui uma inspiração estilística que nos remete aos Ensaios de Montaigne, aos Pensamentos de Pascal e ao Príncipe de Maquiavel, uma vez que a escrita de Azorín alcança um equilíbrio magistral entre a concisão e a ornamentação. Não obstante, a semelhança dessa obra com as outras três supracitadas deve se limitar ao campo da inspiração estilística, tendo em vista que $O$ Político não atinge ou sequer tinha como objetivo atingir - a profundidade conceitual dos três respectivos filósofos: as máximas da obra certamente possuem um caráter abstrato, mas miram a vida comum e se justificam na medida em que possuem valor prático. Azorín alerta que "as máximas, os métodos, os preceitos só têm um valor relativo; são produtos da experiência; mas nos arriscaremos a dizer que todas as circunstâncias da experiência mais fina, mais prudente, que se reuniram em um caso se reunirão em outro?" (2015, p. 121).

O livro é composto por 47 máximas e um epílogo - este intitulado de Epílogo Futurístico. Cada máxima se apresenta como um pequeno capítulo que se estende em média por duas páginas que, em adição ao prefácio e as notas textuais, totaliza o conjunto da obra em 131 páginas. Na edição brasileira, o texto principal é precedido por um prefácio escrito por Alessandro Pinzani (professor de Filosofia Política na UFSC) de título Azorín, o "Inatual"? no qual contextualiza e discute acerca da relevância atual da obra de Azorín, estabelecendo ainda relações de semelhança e dissemelhança entre o autor e Nicolau Maquiavel. Já ao final do texto principal há 24 notas que ajudam o leitor a compreender quem foram algumas 
das ilustres figuras mencionadas no decorrer da obra, como Diego de Saavedra Fajardo (nota 6) e Dom Rodrigo Calderón (nota 18); as notas ainda apontam alguns dos critérios usados no processo de tradução e apresentam não só as palavras em sua versão original no espanhol mas os porquês da escolha daquela palavra em português - como é o caso da primeira nota, sobre a tradução da palavra "fortaleza" por "força". O fato dessas notas se encontram ao final do livro - ao invés de serem notas de rodapé - é uma vantagem dessa edição, uma vez que as notas acabam por não poluir o corpo do texto e tornam a leitura fluida e agradável.

As 14 primeiras máximas certamente causarão estranhamento ao leitor contemporâneo por serem ora extravagantes, ora inatuais. A primeira discute sobre os alimentos que um político deve consumir, a segunda aborda o tipo de roupas que ele deve vestir, a décima terceira sugere que ele não deve se exibir publicamente ${ }^{1}$, etc. No entanto, a partir da máxima 15, Azorín muda o seu estilo de escrita e passa a aumentar o grau de abstração de sua narrativa. $\mathrm{Na}$ máxima 15, por exemplo, intitulada $O$ Direito e a Força, Azorín defende que a força é o que determina todo o jogo político (2015, p. 47), fazendo alusão e eco às lições de Maquiavel em $O$ Príncipe. Das máximas 16 à 20, encontramos diversas anedotas envolvendo figuras ilustres da Espanha e, a partir desse ponto, a obra se torna um misto de estilos literários: torna-se aforismática, dissertativa e anedótica. E assim segue a obra até o desfecho: com máximas sobre o equilíbrio do eu ( $\left.\mathrm{n}^{\circ} 28\right)$, a capacidade de escutar $\left(\mathrm{n}^{\circ} 31\right)$, os benefícios e malefícios da leitura dos clássicos $\left(\mathrm{n}^{\circ} 40\right)$ e do ato de não duvidar de si $\left(n^{\circ} 45\right)$. No Epílogo Futurístico, o estilo da obra se torna dialógico e a temática se refere à formação das cidades, à exploração dos trabalhadores envolvidos em árduas atividades industriais e até mesmo à genealogia da pobreza. Podemos constatar,

${ }^{1} \mathrm{O}$ estranhamento por causa da inatualidade dos conselhos se torna aparente na medida em que hoje, na sociedade do espetáculo em que vivemos, o político deve se exibir excessivamente tanto na grande mídia como na internet, mostrando não apenas que ele é competente em seu ofício, mas carismático.

Cad. Trad., Florianópolis, v. 38, no 2, p. 392-399, mai-ago, 2018 
então, que nesse sentido $O$ Político é uma obra plural no que diz respeito às temáticas abordadas e à estilística, sendo esta sempre elegante e composta de um vasto e rico vocabulário - o que pode se tornar um desafio para o tradutor na medida em que cada estilo pode exigir critérios de tradução específicos. Analisaremos então os pontos em que a tradução da obra foi bem sucedida ou não a respeito da preservação da estrutura de sua composição narrativa.

Podemos constatar que Azorín faz um uso recorrente do ponto e vírgula. A razão para o uso dessa pontuação reside na própria estrutura do texto: cada máxima trata de um conceito em específico, de modo que a narrativa progride linearmente a partir desse único ponto. Assim, Azorín não precisaria escrever um número elevado de parágrafos ou usar pontuações que dividissem as suas ideias. Dessa forma, o ponto e vírgula se mostra como uma ferramenta atraente. No entanto, na língua portuguesa, o uso do ponto e vírgula é circunscrito, uma vez que transmite certa formalidade - o que pode ser inadequdo para algumas passagens de $O$ Político. $\mathrm{O}$ tradutor, por sua vez, parecia estar ciente desse desafio e, como se pode notar nas passagens abaixo, ora preservou o ponto e vírgula, ora o substituiu por outras pontuações, de acordo com a exigência de cada passagem do texto. Na máxima $2, A$ arte de vestir-se, encontramos um caso de manutenção parcial da pontuação:

"No está en la maestría del sastre que nos viste; está en nosotros. Está en la conformación de nuestro cuerpo; en los movimientos; en la largura o cortedad de los miembros; en el modo de andar, de saludar, de levantarse" $(1984$, p. 8$)$

“Não está na maestria do alfaiate que nos veste, está em nós mesmos. Está na forma de nosso corpo; nos movimentos; na forma alongada ou curta dos membros; no modo de andar, de saudar, de se levantar, de se sentar." (2015, p. 19) 
Porém, na máxima 6 , Remediar a inadvertência, a pontuação é largamente modificada:

"Estaban una tarde en un huerto los Reyes Católicos don Fernando y doña Isabel; se hallaban con ellos muchos caballeros y damas de la corte; para solazarse y pasar el rato idearon un juego." (1984, p. 13)

"Estavam certa tarde em um jardim os reis católicos Dom Fernando e Dona Isabel. Achavam-se com eles muitos cavalheiros e damas da corte. Para distraírem-se e passarem o tempo inventaram um jogo." (2015, p. 29)

E o mesmo ocorre na máxima 1, Deve ter força:

"Ha de comer poco también; sea frugal; tenga presente que no es el mucho comer lo que aprovecha, sino el bien digerir. En sus comidas tome espacio y sosisego; coma lentamente, como si no tuviera prisa por nada" $(1984$, p. 7$)$.

"Deve comer pouco também. Seja frugal, tenha em mente que não é a quantia que ele come que ele aproveita, mas a que digere. Tenha tempo e tranquilidade para suas refeições. Coma lentamente, como se não tivesse pressa com nada" $(2015$, p. 17)

Essa característica se prolifera no decorrer de todo o texto, sendo múltiplos os exemplos desse caso. Podemos afirmar que a manutenção e a modificação da pontuação foi realizada com maestria e que em nenhum momento da leitura sentimos um estranhamento ou uma quebra de ritmo. A tradução apresenta uma cadência adequada, o que torna a leitura do texto agradável, coerente e ininterrupta.

Além do caso das pontuações, há momentos em que o tradutor acresce informações ao texto original para que o leitor brasileiro seja 
capaz entender as referências apresentadas por Azorín, sem a necessidade de se dirigir às notas finais. De um modo geral, as adaptações facilitam a leitura sem distorcer ou simplificar o texto original. É o caso da máxima 20, Arte no vestir-se. Nessa passagem:

"Véase también el efecto de este matiz y paliativo en el retrato que figura en nuestro Museo del magistrado don Diego de Corral, pintado por Velázquez" (1984, pp. 8-9, itálicos nossos)

"Veja-se também o efeito deste matiz e disfarce no retrato do magistrado Dom Diego de Corral, pintado por Velázquez, que está no Museu de Madri" (2015, p. 20, itálicos nossos)

Queremos chamar atenção à tradução de "nuestro Museo" por "Museu de Madri". A tradução não teria sido clara se fosse literal (nesse caso, "nosso museu"), uma vez que não há qualquer menção à cidade de Madrid no decorrer das máximas. Se um leitor, em uma tentativa de contextualizar essa passagem, fosse buscar na contracapa do livro o nome da cidade na qual Azorín nasceu (a saber, Monóvar) a informação obtida seria equivocada porque Azorín não está se referindo ao museu de Monóvar nessa passagem. Uma nota ao final do texto poderia ter sido usada, mas essa atitude interromperia a fluidez da leitura da obra. Portanto, a adaptação da tradução deve ser vista com bons olhos. Porém, na máxima 22, Ter alguma qualidade distintiva, a adaptação não seria necessária:

"Se echó sobre sí para ablandar a la mocita un bolsillo com trescientos doblones" (1984, p. 49, itálicos nossos)

"Carregou nas costas, para amolecer a moça, uma bolsa com trezentos reais" (2015, p. 66, itálicos nossos) 
O doblón era uma antiga moeda de ouro usada na Espanha; e a referência às moedas, por estarem a ser carregadas em uma bolsa, pode também indicar as noções de peso e esforço. No entanto, o uso do substantivo "real", em referência à moeda corrente usada no Brasil, causa um estranhamento em ao menos dois sentidos: no primeiro, por não captar a noção de peso e esforço; no segundo, porque Azorín nessa passagem está reconstruindo uma história antiga, que aponta para uma rusticidade que uma moeda contemporânea - mesmo que fosse o "euro", no caso da história se passar na Espanha - não consegue captar. Desse modo, acreditamos que a melhor tradução para doblones seria "moedas de ouro", pois denotaria tal rusticidade e ainda não causaria estranhamento ao leitor brasileiro. Uma nota de referência ao significado de doblón também poderia ser apresentada, no caso dessa escolha.

Na tradução da máxima 22 ainda encontramos uma ambiguidade, que se mostra a seguir:

"Yo, señor, soy hombre de bien, hijodalgo, y com tan grande necesidad, que una hija que tengo de diecenueve años y yo nos hemos desayunando desde anoche por no tener, ni sabemos lo que ha de ser de nosotros (...)" $(1984$, p. 49)

"Eu, senhor, sou homem de bem, generoso, e com tanta necessidade que eu e uma filha de dezenove anos que tenho desde ontem à noite não comemos nada por não termos nada, nem sabemos o que há de ser de nós (...)” (2015, p. 66, itálicos nossos).

A ambiguidade está na passagem "eu e uma filha de dezenove anos que tenho desde ontem à noite"; por mais paradoxal que seja afirmar que alguém tem uma filha de dezenove anos há um dia, ao ponto em que o leitor que detectar a ambiguidade prontamente descartará a opção paradoxal e não incorrerá em dúvida ou confusão, poder-se-ia diluir a ambiguidade traduzindo essa passagem como 
“(...) e com tanta necessidade que desde ontem à noite eu e minha filha de dezenove anos não comemos nada por não termos nada (...)". Não encontramos qualquer outro problema no decorrer da leitura do texto, de modo que estamos certos de que a tradução da obra se mostra exemplar.

Por fim, podemos afirmar que a leitura de $O$ Político é importante para a compreensão do espírito de uma época na Espanha. Mesmo que alguns dos conselhos encontrados na obra possam causar estranhamento para o leitor contemporâneo, outros certamente podem nos fazer compreender vários aspectos referentes à vida em sociedade. O estilo rebuscado do autor é um dos atrativos da obra, e a edição brasileira captura essa característica com primor. As sugestões de aprimoramento da tradução são escassas ou praticamente inexistentes, o que demonstra que o leitor brasileiro tem uma excelente edição ao seu dispor; de modo que Azorín, um dos clássicos da literatura espanhola, teve uma tradução inaugural para o português à altura do que se espera de um escritor de tal relevância.

\section{Referência}

AZORÍN. O Político. Tradução de Jaimir Conte. Florianópolis: EdUFSC, 2015, $131 \mathrm{p}$.

Recebido em: 20 de dezembro de 2017

Aceito em: 14 de fevereiro de 2018 Publicado em: maio de 2018

İtalo Lins Lemos. E-mail: italolinslemos@hotmail.com 